Laboratorio de Arte,4-1991 http://dx.doi.org/10.12795/LA.1991.i04.09

\title{
VALDÉS LEAL Y LA ARQUITECTURA SEVILLANA*
}

\author{
por TeOdoro Falcón Márquez
}

\begin{abstract}
Valdés Leal fue sin duda el más barroco de la pintura española del siglo XVII y el mejor compositor de arquitecturas de la pintura barroca sevillana. Estuvo presente en la decoración de los principales edificios sevillanos construidos en la segunda mitad del siglo XVII. A lo largo de su vida profesional se mostró como un gran escenógrafo, no sólo en la realización de arquitecturas efímeras, sino en la decoración arquitectónica de gran número de templos.

Valdés Leal was without doubt the most baroque Spanish painter of the 17th century and the best of all the Sevillian baroque artists at architectural composition. He was involved in the decoration of the most important buildings constructed in Seville in the second half of the 17th century. Throughout his working life he demonstrated his ability as a great scenographer, not only in temporary structures but also in the architectural design of a great number of churches.
\end{abstract}

A pesar de la importante bibliografía existente sobre Valdés Leal, con aportaciones documentales y revisiones críticas realizadas por Gestoso, Duncan T. Kinkead y Valdivieso, entre otros, siguen existiendo algunas lagunas en la vida y obra de este pintor sevillano. Sin duda uno de los aspectos menos conocidos es su labor como arquitecto, título con el que figura en algunos documentos. Además de dibujar y grabar la custodia de Arfe en 1668, figura como tracista de arquitecturas efímeras, tales como el Triunfo de San Fermando, erigido en 1671 en la catedral de Sevilla, con motivo de su canonización, y en 1680 en el Monu-

* Resumen de la conferencia dada el 24 de abril de 1991 en la Facultad de Geografía e Historia de la Universidad de Sevilla, dentro del Ciclo sobre Valdés Leal. 
mento de Semana Santa para la iglesia de Santa María de Arcos, que contrata con el escultor Fernando de Barahona.

Estoy convencido que debió hacer también dibujos arquitectónicos. Uno de los argumentos que podemos esgrimir es que de su hijo Lucas Valdés, que tanto siguió los pasos de su padre, está documento que hizo las trazas de la portada de la capilla sevillana de San José, en 1716. En este contexto hay que recordar que fue profesor de Dibujo en la Academia fundada en 1660 por Murillo y Herrera el "Mozo" en la antigua Lonja, en donde llegó a ser Director, cuyo plan docente -de carácter práctico - estaba en base al Dibujo y al Modelado. Es de suponer que además del dibujo artístico se enseñaría el lineal, tomado fundamentalmente de estampas.

Lo cierto es que Valdés hace un uso constante de fondos arquitectónicos en la mayoría de sus composiciones, lo que evidencia un gran conocimiento de la Arquitectura, tanto en lo que podríamos llamar análisis de elementos arquitectónicos, como de la perspectiva. Por otra parte, Valdés se va a mostrar a lo largo de toda su vida profesional como un gran escenógrafo, no sólo en la realización de arquitecturas efímeras, sino en la decoración arquitectónica de gran número de templo. Estuvo presente en la decoración de los principales edificios sevillanos construidos en la segunda mitad del siglo XVII. Por razones generacionales lamentablemente apenas coincidió con Leonardo de Figueroa, que entonces comenzaba su carrera profesional a fines de la década de 1680 . Con él posiblemente la obra de Valdés hubiera adquirido dimensiones insospechadas.

Como veremos, los fondos arquitectónicos de Valdés son reales, no de "cartón piedra" como muchos de los de Zurbarán. En la mayoría de los casos se inspira en edificios religiosos sevillanos contemporáneos en los que él va a participar, así como también toma referencias de los grandes tratadistas de la arquitectura italiana del Renacimiento y de Fray Lorenzo de San Nicolás. Ello ratifica la afirmación de Palomino, de que era "un hombre erudito y práctico en el orden de la pintura... grandísimo dibujante perspectivo, arquitecto y escultor excelente".

En la pintura española del siglo XVII un lugar común de muchos pintores a la hora de representar el marco arquitectónico más elemental será el de colocar como fondo una columna sobre un pedestal. Generalmente suele ser siempre de orden toscano. De los tratados italianos, el que tuvo más difusión en esta época fue el de Arquitectura de Viñola, del que la primera edición española se hizo en 1593 y en el siglo XVII hubo dieciséis ediciones en toda Europa. Es significativo que Viñola recomiende el orden toscano como "el más propicio para templos y para todo lo que pida un carácter de estabilidad y confianza".

Este tipo de soporte lo emplea Zurbarán en el cuadro de Fray Gonzalo de Illescas, de Guadalupe (1639) y en el San Bruno visitando a Urbano II del Museo de Sevilla, procedente de la Cartuja (¿1623 ó 1655?). También lo utiliza frecuen- 
temente Murillo, como en el San Isidoro de la catedral de Sevilla (1655), en la Anunciación del Prado (1650-55), o en el Patricio Juan y su esposa ante el papa Liberio, del Museo del Prado (1665), entre otros.

La serie de pinturas de Valdés Leal donde aparece como marco arquitectónico la columna, coincide con la cronología de Murillo, cuando tras su etapa cordobesa se va a afincar en Sevilla. El punto de partida es el conjunto de cuadros que hizo para el monasterio de San Jerónimo, realizado entre 1656-57. Entre ellos destacaremos el San Jerónimo, Santa Paula y Fray Hernando de Talavera (lám. 1). Creo que la decoración floral del basamento de la columna toscana está tomada del libro I de Arquitectura de Palladio, traducido en 1616. La huella de este tratadista en Sevilla se halla patente en la fachada del Hospital de la Caridad y en el patio de la Lonja, entre otros edificios, además de en retablos. La columna de orden toscano sobre basamento lo repetirá Valdés en el lienzo de la Liberación de San Pedro, de la catedral de Sevilla (1657-59).

Mayor interés ofrece el lienzo de Fr. Pedro de Cabañuelas, del Museo de Sevilla (1656-57). A diferencia del cuadro de Zurbarán del mismo tema, aquí se suprime el paisaje arquitectónico, mostrando un retablo con una columna salomónica. Si cotejamos esta columna de Valdés con las que existen en el terreno artístico de la época podremos apreciar que nada tiene que ver con las de $\mathbf{R u}$ bens, de los Triunfos para los tapices de las Descalzas Reales (1627).

Tampoco con las que ilustran el Tratado de Pintura Sabia de Fr. Juan Rizi, realizado en 1663. Ni con el frontispicio de un libro que contribuyó a difundir la columna salomónica en Hispanoamérica: Flores de Miraflores, hieroglíficos sagrados, verdades figuradas, sombras verdaderas del misterio de la Inmaculada Concepción de la Virgen y Madre de Dios, María Señora Nuestra, publicado en Burgos en 1659, siendo su autor el cartujo burgalés Fr. Nicolás de la Iglesia. Este raro ejemplar fue dado a conocer por Bonet Correa.

Estimo que el punto de referencia del cuadro de Valdés se halla en el retablo de la Concepción Grande, de la catedral de Sevilla. Su ejecutor fue el maestro entallador Martín Moreno. La carta de pago está fechada en 1658, cuando el retablo se hallaba sin concluir. Se da la circunstancia de que en este mismo año Valdés colaboró con Martín Moreno en la realización de un retablo doméstico para Juan López de Sevilla. El diseño de las trazas del retablo de la catedral se ha atribuido a Francisco Dionisio de Ribas, de quien una hija suya se casó con Lucas Valdés.

Otros autores han atribuido este diseño a Bernardo Simón de Pineda, con quien Valdés tendrá frecuentes vínculos familiares y profesionales. Creo que Valdés debió ver el boceto de este retablo, del que hemos dicho que se pagó -sin concluir- en 1658, siendo el cuadro de Valdés de 1656-57. Este artista realizaría también en esta capilla el dorado de la reja y la lápida conmemorativa de su patrono, Gonzalo Núñez de Sepúlveda. 
Un fondo arquitectónico con columna salomónica figura también en el lienzo de Los Desposorios de la Virgen y San José de la catedral de Sevilla (1657), donde figura una decoración con yeserías, que como veremos responde a una vieja tradición en Sevilla, iniciada en el período del protobarroco por Juan de Oviedo (lám. 2). En este mismo año pintó Valdés el cuadro de Fr. Vasco de Portugal, para el monasterio de San Jerónimo de Sevilla, actualmente en el Museo de Dresde. En el patio que figura al fondo hay ventanas con orejetas, como es frecuente en la Sevilla de la época. El claustro se culmina con un frontón roto, con penacho central, tema extraído del tratado De Arte y uso de la Arquitectura, de Fr. Lorenzo de San Nicolás (1633).

En 1662 se concluyó la iglesia del Sagrario, ubicada en uno de los riwaq de la antigua mezquita mayor almohade. Hace unos años (1977), en mi monografía sobre esta iglesia, documenté que Valdés realizó tres lienzos para decorar la cabecera del templo. El del centro representaba el Crucificado, acompañado por la Virgen y San Juan; a la izquierda del espectador, a Jesús atado a la columna, y a la derecha, el tema de la Sentencia. Por razones obvias estos cuadros expuestos a la intemperie se fueron deteriorando progresivamente, de tal modo que ya en 1694 tuvieron que ser restaurados por Miguel Parrilla. Se conserva un testimonio gráfico sobre la ubicación de estas pinturas, en el cuadro de 1747 atribuido a Domingo Martínez, existente en el Museo de Sevilla, que representa la mascarada de los empleados de la Fábrica de Tabacos, con motivo de la exaltación al trono de Fernando VI. En los antepechos de la tribuna que hay en esta fachada de la iglesia hay relieves alusivos a estos temas. En el centro clavos y tenazas; a la izquierda la columna y el látigo, y a la derecha una escalera y un farol.

El interior de la iglesia está decorado con yeserías labradas por Pedro y Miguel de Borja, realizadas entre 1652-56, así como con esculturas de José de Arce, de 1656 , que representan alternativamente a los Padres de la Iglesia y a los Evangelistas. Cuando falleció Arce en 1666 Valdés adquirió a su viuda los útiles de escultura, ya que ésta fue otra de las actividades de este artista, de la que han quedado pocos testimonios, como la Inmaculada del Hospital de la Caridad.

Simultáneamente a estos acontecimientos, Valdés pintó la serie sobre la vida de San Ignacio, para el çlaustro de la Casa Profesa de Sevilla (1660-64). Uno de estos lienzos, San Ignacio exorcitando a un poseso, se halla actualmente en el Museo de Sevilla. Al parecer la escena que aparece al fondo alude a la estancia del santo en Manresa. Según Valdivieso, el grupo está inspirado en un grabado de Adrián Collaert, editado en Amberes en 1610. Sin embargo, la torre-mirador que figura al fondo es sevillana. En esta época había dos variantes de miradores: con arquerías sobre columnas, o sobre pilares, que es como se representa aquí, de cuyo prototipo se conservan algunos modelos, como por ejemplo en la Plaza del Cristo de Burgos.

También es característico de esta época en Sevilla los patios con columnas 
dórico toscanas, con un cimacio sobre su capitel. Este modelo de soporte lo va a encontrar Valdés en la mayoría de los edificios donde va a intervenir; citaremos, entre otros, el Palacio arzobispal, la iglesia de Santa María la Blanca y el Hospital de la Caridad. En el cuadro de San Antonio con el Niño, de Murillo, existente en la capilla del Bautismo de la catedral (1656), tiene como fondo la perspectiva de un claustro, que según Palomino se debe a la intervención de Valdés. Este fondo arquitectónico de columnas con cimacio, del mismo tipo que las citadas anteriormente, se halla también en el cuadro de San Francisco recibiendo la ampolla de agua, de Valdés, existente en el Museo de Sevilla (1660-65) (lám. 3). Creo que en ambos casos la perspectiva está tomada de un mismo patio, el Claustro Grande del convento de San Francisco, y más exactamente, desde el tránsito donde se hallaba la escalera principal. Este mismo tipo de soporte lo emplea Valdés en Las bodas de Caná, del Louvre (1660-64) y en algunos cuadros de la serie de la vida de San Ambrosio, para el Palacio arzobispal (1673).

Otro fondo arquitectónico reiterado por Valdés es el de una escalera, de giro a la derecha, con antepecho de balaustres y pequeños pilares de refuerzo rematados en esferas, además de suelos de olambrillas. Este escenario, con pequeñas variantes, aparece en el cuadro de las Bodas de Caná, actualmente en una colección particular de Madrid (1660-64); en el Milagro de las abejas, del Museo de Sevilla (h. 1673) y en La Danza de Salomé, de una colección particular de Madrid (h. 1676) (lám. 4). En todos ellos hay una serie de elementos comunes, tales como la escalera, columnas, reja, etc., que tienen gran semejanza con el Palacio arzobispal.

En este edificio trabaja Valdés hacia 1673 en el Oratorio Bajo, por encargo del cardenal Ambrosio Spínola. Con relación a la escalera de este palacio, la bibliografía tradicional afirma que se debe a Fr. Manuel Ramos (1697-1701), en tiempo del arzobispo Palafox. Llaguno, sin embargo, sostiene que entonces fue "reparada". Efectivamente, una escalera se hizo en tiempos de Antonio Paino (1663-69), cuyo escudo preside en la clave de la bóveda, por lo que Valdés pudo inspirarse en ella, siendo restaurada posteriormente.

Uno de los edificios más singulares de esta época es la iglesia de Santa María la Blanca, antiguo templo gótico-mudéjar erigido en el solar de una sinagoga. La reconstrucción, promovida por el canónigo Justino de Neve, se llevó a cabo entre 1660-65, seguramente bajo la dirección de Pedro Sánchez Falconete, como hemos dicho en otro lugar. Está documentado la intervención aquí de Pedro Roldán en una capilla en 1660, que debe ser la antigua Sacramental, que no se ha conservado, ya que la actual es moderna. Del equipo de decoradores de Sánchez Falconete en el Sagrario sólo está documentado en estas fechas Pedro de Borja, quien debió realizar las yeserías en Santa María la Blanca desde 1663 a 1665.

En este rico programa decorativo a base de cortezas, hojarascas y ángeles, no sólo en yeserías, sino en pinturas hechas con plantillas, debió intervenir Murillo. 
A él se deben dos lunetos que se ubicaron bajo la media naranja: El Sueño del Patricio y El Patricio ante el papa Liberio; más otros dos que se colocaron en los testeros de las naves laterales: la Inmaculada y la Fe (o la Iglesia triunfante). También hizo para la capilla sacramental la Ultima Cena. Además de Murillo pudo intervenir en la decoración de la iglesia Valdés, a quien se alude en el libro de las Fiestas que celebró la iglesia tras su consagración, editado en 1666, con textos de Torre Farfán. La narración, muy pormenorizada a veces, es en otras parca de noticias, ya que por ejemplo no especifica quién es el autor de las yeserías. A Valdés se le cita como autor de la escenografía que presidía la portada de la iglesia, en donde figuraba una pintura de la Inmaculada.

La ornamentación de las yeserías del Sagrario y de Santa María la Blanca tuvieron su impronta en los fondos de algunos lienzos de Valdés. Entre ellos hay que destacar a Cristo disputando con los doctores en el templo, actualmente en una colección particular de Madrid (1660-64); el San Ambrosio convirtiendo y bautizando a San Agustín, que se conserva en el Museo de Arte de San Luis, procedente del Palacio arzobispal (1673). En el fondo arquitectónico se aprecia el interior de un templo, con superposición de pilastras y con tribuna, además de bóvedas con yeserías, lo que recuerda a la iglesia del Sagrario. Entre 1680-83 realizó las pinturas murales de San Clemente, ubicadas en el testero del coro y en el presbiterio. Algunos de estos temas están relacionados con Santa María la Blanca. También hay que destacar la última pintura sobre lienzo documentada de Valdés, Cristo disputando con los doctores en el templo, del Museo del Prado (1686), en donde sólo es sevillano los paramentos murales con yeserías (lám. 5).

Otro de los más importantes edificios construidos en Sevilla en esta época es el Hospital de la Caridad, proyectado en 1645 por Pedro Sánchez Falconete. Siguiendo el programa ideológico trazado por Miguel de Mañara, Valdés ejecutó en su iglesia varias pinturas en lienzo y al fresco. Hacia 1671 realizó los Jeroglíficos de las Postrimerías. En "In ictu oculi" yacen al pie del símbolo de la muerte una serie de atributos del poder eclesiástico y del civil, así como unos libros que evidencian lo efímero de la sabiduría y de la erudición. Por su ilustración, uno de los libros ha sido identificado por Mayer como Pompa con que la ciudad de Amberes solemnizó la entrada en ella del infante D. Fernando de Austria, editado en 1642. En este libro abierto figura una arquitectura efímera, que representa un arco de triunfo. Conviene recordar que la realización de este lienzo es contemporáneo del Triunfo de San Fernando y otras arquitecturas efímeras en la catedral de Sevilla (lám. 6).

De este acontecimiento, con motivo de la canonización de Fernando III, existe un importante documento gráfico, el libro de Fernando de la Torre Farfán Fiestas de la Santa Iglesia metropolitana y patriarcal de Sevilla al nuevo culto del Señor Rey S. Fernando, Sevilla, 1671. La publicación está ricamente ilustrada con grabados de Matías de Arteaga y de Valdés Leal y sus hijos, entre ellos 
Lucas, que contaba con 11 años. Por iniciativa de Valdés, el Cabildo catedral aprobó ubicar el Triunfo en el Trascoro, en el mismo lugar donde se colocaba el Monumento de Semana Santa. Según la documentación existente en el Archivo catedral sus arquitectos fueron Valdés y Bernardo Simón de Pineda. El primero figura en un grabado, delante del Triunfo, exponiendo su proyecto a unos religiosos. Simón de Pineda se representa a la derecha, dirigiendo la toma de medidas (lám. 7).

El monumento a San Fernando, de cuatro frentes y unos 30 metros de alto, estaba concebido como un arco de triunfo, de esquema serliano-palladiano, con óculos. En su programa iconográfico figuraban alusiones a los cuatro reinos conquistados por el santo rey: Murcia, Jaén, Córdoba y Sevilla, más los trofeos y estandartes. Sobre una cúpula de ocho paños se hallaba una pintura con la procesión de San Fernando, entrando en Sevilla con el "paso" de la Virgen de los Reyes. El tema lo repetirá posteriormente en la fachada del coro de San Clemente. El conjunto se remataba con una colosal estatua del rey, de unos tres metros de alto, entrando en la gloria, fingida en la bóveda central de la catedral.

En la fachada interior del templo, a los pies, Valdés diseñó otra escenografía, una portada efímera también de esquema serliano-palladiano, con superposición de arco y dintel, rematada con el estandarte real. En el grabado figura de nuevo Valdés mostrando el proyecto a unos miembros del Cabildo catedral; también aparece un grupo de músicos tocando en la tribuna. Desde el punto de vista escenográfico y espacial, es interesante la dualidad dentro-fuera que plantea, al ofrecer una vista de la calle Génova (actual Avenida) y a la derecha una representación de la misma fachada desde el exterior.

El gasto total de estas escenografías ascendió a 13.400 ducados (unos 285.000 reales). Según los documentos inéditos que aportamos, Valdés percibió más que Simón de Pineda. En la documentación figuran los artistas que colaboraron, entre los que aparecen Sebastián Martínez, Gaspar Plus, Juan Bijer y Jacinto Serrano.

Otra de las grandes realizaciones arquitectónicas de la época fue el Hospital de los Venerables, proyectado por Juan Domínguez y proseguido por Leonardo de Figueroa a partir de 1686. En junio de este año inició Valdés la decoración del cuerpo de la iglesia, con pinturas al temple y al óleo, contando con la colaboración de su hijo Lucas Valdés. Estas pinturas aluden al ministerio sacerdotal. Más interesantes desde el punto de vista arquitectónico es la decoración de la Sacristía, realizada entre 1687-88. Se trata de una estancia que mide aproximadamente $8 \times 4 \mathrm{~m}$., con un techo muy bajo. Valdés la decoró con una Alegoría del Triunfo de la Cruz, consiguiendo a través de una inteligente perspectiva darle una mayor profundidad a la cubierta. Es muy posible que Valdés se haya inspirado en el jesuita Andrés Pozzo (1642-1709), autor de Perspectiva de pintura y arquitectura (lám. 8).

Como ya hemos adelantado, entre 1680-83 intervino en la decoración mural 
de la iglesia de San Clemente, ubicada principalmente en la fachada del coro y en el presbiterio. En el testero del coro preside San Fernando entrando en Sevilla, tema que como hemos dicho es similar al del Triunfo de la catedral; en el resto de la decoración figuran las armas reales y cortezas, cuyo repertorio está relacionado con la decoración de Santa María la Blanca, lo que se hace más patente en el presbiterio. Con el fallecimiento de Valdés el 15 de octubre de 1690 se puso fin a la obra de este artista polifacético, sin duda el más barroco de nuestra pintura del siglo XVII y el mejor compositor de arquitecturas en la pintura barroca sevillana. 


\title{
APÉNDICE DOCUMENTAL
}

\author{
1
}

1671 Enero, 19. Sevilla. Estampa de San Fernando para Roma. Archivo catedral. Sección VIII (Varios), n.. 37 (7). con firma autógrafa de Valdés Leal.

Manden Vms. señores contadores mayores de esta Santa Iglesia librar doscientos reales de vellón a Juan de Valdés, maestro pintor, por la estampa que ha hecho del santo rey D. Fernando, para abrir lámina en Roma. Fecho en Sevilla en 19 de enero de 1671 (rúbricas).

Los señores llaveros de la caja de los depósitos de esta Santa Iglesia de la cuenta del santo rey D. Fernando, vms. pagarán a Juan de Valdés, maestro pintor de esta ciudad, doscientos reales que valen 6.800 mrs. por la estampa que ha hecho del santo rey para abrir lámina en Roma, y librósele en virtud de certificación de arriba y tomen vms. su recibo, fecho en Sevilla en 19 de enero de 1671 años (rúbricas).

Recibi los doscientos de arriba en 26 de enero de 1671. Juan de Valdés Leal.

1671 Relación de gastos del triunfo*.

Relación de los gastos que se han hecho en la Fiesta del Santo rey don Fernando, así luego que vino el Breve, de la misa y rezo, como el Triunfo y fuegos y otros gastos que se hicieron por mano de los señores don Justino de Neve y don Juan de Loaysa, diputados del Triunfo y don Andrés de León. don Antonio Garcés y don Diego de la Cueva, diputados, y para los demás gastos de fuegos y procesiones que todo es en la manera siguiente, conforme la Memoria que dichos señores han entregado.

Gastos luego que vino el Breve

Primeramente 1.706 rs. $1 / 4$ al Sr. Mateo Coello, para que pague las albricias al Correo Mayor y sus oficiales y al extraordinario que trajo el pliego de Roma con la Bula de misa y rezo del santo rey don Fernando.

En los fuegos y luminarias que se hicieron tres noches $4.526^{12}$

Item 400 rs. que se dieron a la Capilla Real para ayuda a la cera que gastó.

Item 460 rs. a Pedro Muñoz, maestro herrero, por el aderezo del cepo que se puso para la limosna.

\section{Gastos hechos del Triunfo}

Primeramente 58.091 rs. a Juan de Valdés, pintor, los 47.091 rs. por los jornales que se pagaron por su mano y los 11.000 rs. que Vs. le dio de ayuda de costa.

Item 47.301 rs. a Bernardo Simón, maestro escultor, los 36.301 rs. por lo jornales que se pagaron a maestros carpinteros, oficiales y peones y los $11.000 \mathrm{rs}$. que Vs. le mandó de ayuda de costa.

Item 11.970 rs. que se pagaron a Gaspar Plus por el lienzo que dio.

\footnotetext{
* Todos estos documentos se hallan en el mismo expediente.
} 
Item 22.929 rs. que se pagaron a Josua Kambel por la tablazón y madera que dio.

Item 1.092 rs. a Francisco Mucio por el papel de marca mayor que dio para el Triunfo.

Item 10.045 rs. a Juan Bijer por el velillo que dio para el Triunfo.

Item 1.940 rs. a Jacinto Serrano por más velillo que dio.

Item 3.030 rs. que hicieron de costa los clarines en que entra la ayuda de costa que se les dio.

Item 3.000 rs. a Gonzalo Ruiz, por colgar las portadas, pilares del Triunfo y de entre coros.

Item 9.813 rs. a Luis de Salafranca, por la franja de plata y oro para el velillo que dio.

Item 4.348 rs. a Sebastián Martínez por el raso y tafetán que dio para las estampas que se hicieron por mandato de los señores diputados del Triunfo.

Item $903 \mathrm{rs} .{ }^{1 / 2}$ a Juan Antonio González por las puntas de oro que dio para las estampas.

Item 1.248 rs. a Juan Ordóñez por la franja de oro y plata que dio.

Item $1.424 \mathrm{rs} .{ }^{12}$ a Pedro serrano y José Ramírez por la holandilla que dieron.

Item 9.412 rs. que se pagaron por orden del Sr. Don Fernando Bazán por el velillo que remitió de la ciudad de Córdoba.

Item I.800 rs. a Pedro de Campolargo por las estampas que hizo.

Item 300 rs. a la persona que abrió la lámina del santo rey don Fernando.

Item 800 rs. de las vitelas, escribir las cédulas y luminarias.

Item $500 \mathrm{rs}$. de portes de colgaduras.

Item 230 rs. de limpiar las gradas.

Item 354 rs. a los sastres que cosieron las colgaduras.

Item 350 rs. de los almuerzos que se dieron a los oficiales.

Item 530 rs. a los barqueros por traer y llevar las banderas y gallardetes de Cádiz.

Item $4.680 \mathrm{rs}$. que se gastaron en desbaratar el Triunfo.

Item 1.000 rs. al Sr. Don Francisco Ponce para que los dé al padre Pedro de Esquivel por el trabajo de la misa y rezo que hizo que se remitió a Roma.

Montan los gastos del Triunfo $82.955 \mathrm{rs}$.

Gastos hechos en los fuegos, efigie del santo y otros

Por mano del Sr. Don Andrés de León y señores oficiales de fábrica se gastaron 80.765 rs. en las partidas siguientes:

En los vestidos de los seises $14.997^{1 / 2} \mathrm{rs}$.

Manto y espada para el santo rey $18.688^{12}$.

Hechura del santo rey, peana y estofo (sic) 7.300 .

De la corona a toda costa 9.019 .

Fuegos de la torre 7.200 .

De la fábrica del castillo de la Lonja, de lienzo, pintura, madera, clavazón y hechura 4.200.

De los fuegos de la Lonja en dicho castillo 9.300 .

De los barriles que se pusieron en todas las gradas 2.000 .

De la láminas que se abrió, tafetán, vitelas, papel y hechura de las estampas del santo rey don Fernando 5.300.

Del desbarato de la compra de terciopelo que se había mandado traer para colgaduras 1.300 .

A los ministriles de fuera 700 .

A los clarines de la ciudad 160.

De holandilla para gallardetes 600.

Total: 80.765 . 
Los señores Contadores Mayores deben las partidas abajo mencionadas que han librado para diferentes gastos de las fiestas del santo rey.

- En 14 de abril a Juan de Valdés

- En dicho día a Francisco Mucio

- En 15 del dicho al Sr. Don Andrés de León

- En dicho día a dicho señor

- En 17 del dicho a Juan de Valdés ......................................................... $\quad 5.000$

- En dicho día a Bernardo Simón ........................................................... $\quad 3.000$

- En dicho día a dichos señores ............................................................ $\quad 6.000$

- En 18 de abril de $167 \mathrm{l}$ a Juan de Valdés ............................................. $\quad 2.000$

- En 20 de abril de 1671 a Juan de Vijer ............................................. 4.740

- En 22 del dicho a Juan de Vijer ........................................................... 2.340

- En dicho día a Bernardo Simón ........................................................... $\quad 2.000$

- En 23 de abril de 1671 al Sr. Don Andrés de León .............................. 11.000

- En dicho día a Juan de Valdés ............................................................. $\quad 3.000$

- En 25 de abril de 1671 a Juan de Valdés .......................................... $\quad 2.500$

- En 26 del dicho a Juan de Valdés ........................................................ 2.000

- En dicho día a Bernardo Simón ...................................................... $\quad 2.000$

- En 28 de abril de 1671 a Juan de Valdés ............................................. $\quad 2.000$

- En dicho día a Bernardo Simón ............................................................. $\quad 2.000$

- En 28 de abril al Sr. D. Andrés de León .............................................. 8.000

- En dicho día a Juan de Valdés ............................................................. $\quad 2.000$

- En 30 del dicho a Juan de Valdés ........................................................ $\quad 2.000$

- En 2 de mayo de I67I a Bernardo Simón ............................................... $\quad 3.000$

- En 2 de mayo a Alonso de Salafranca ................................................... 3.549

- En 4 de mayo a Juan de Valdés ........................................................ $\quad 2.000$

- En 5 de mayo de 1671 a Bernardo Simón ............................................. $\quad 2.000$

- En dicho día a Juan de Valdés ........................................................... $\quad 2.000$

- En 8 de mayo de 1671 al Sr. Don Andrés de León ............................... 11.000

- En dicho día a Juan de Valdés ............................................................. $\quad 2.000$

- En 9 del dicho a Bernardo Simón ......................................................... 3.000

- En dicho día a Juan de Valdés .............................................................. 4.000

- En 13 del dicho a Juan de Valdés ........................................................ $\quad 2.000$

- En dicho día a Bernardo Simón ......................................................... $\quad 2.000$

- En 14 de mayo de 167I al Sr. Don Andrés de León ............................... 8.000

- En I6 de mayo a los dichos señores .................................................... $\quad 2.000$

- En dicho día a Bernardo Simón ........................................................... 3.000

- En dicho día a Juan de Valdés .............................................................. 3.000

- En dicho día a D. Miguel de Salafranca …………................................. $1.930^{1 / 2}$

- En 20 del dicho a los dichos señores .................................................... $\quad 3.000$

- En dicho día a Bernardo Simón ............................................................. 2.000

- En dicho día a Juan de Valdés .............................................................. 3.000

- En 13 de mayo a Juan de Vijer ............................................................ $\quad 1.330$

- En 20 de mayo al dicho .......................................................................... 1.635

- En 21 de mayo de 167l a Juan de Valdés ................................................ 2.000

- En dicho día por la letra de Córdoba .................................................... $\quad 4.212$ 
- En 23 del dicho a Bernardo Simón ...................................................... 4.000

- En 23 del dicho a Juan de Valdés ............................................. 3.000

- En 23 del dicho a Jacinto Serrano .................................................. 1.940

- En 23 de mayo de 1671 a Sebastián Martínez ....................................... $\quad 1.638$

- En 4 de junio de 1671 a Bernardo Simón ......................................... 17.101

- En dicho día a Josua Bambel ......................................................... 16.929

- A Juan de Valdés ............................................................................ 13.59 I

- En 6 del dicho al Sr. D. Andrés de León ...................................... 11.747

- En dicho día a Sebastián Martínez ..................................................... 221

- En 6 de junio de I67I a Salafranca .................................................... 4.533

- En 8 de junio a dicho Sr. para puntas .................................................. $150^{12}$

- En II de junio de 1671 a Gonzalo Ruiz ............................................... 1.000

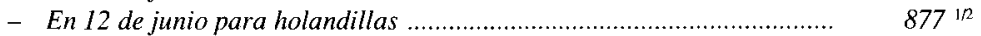

$80.511 \mathrm{rs}^{1 / 2}$

(En este expediente figura también una Memoria de Bernardo Simón de Pineda con los libramientos dados a carpinteros y para materiales). 


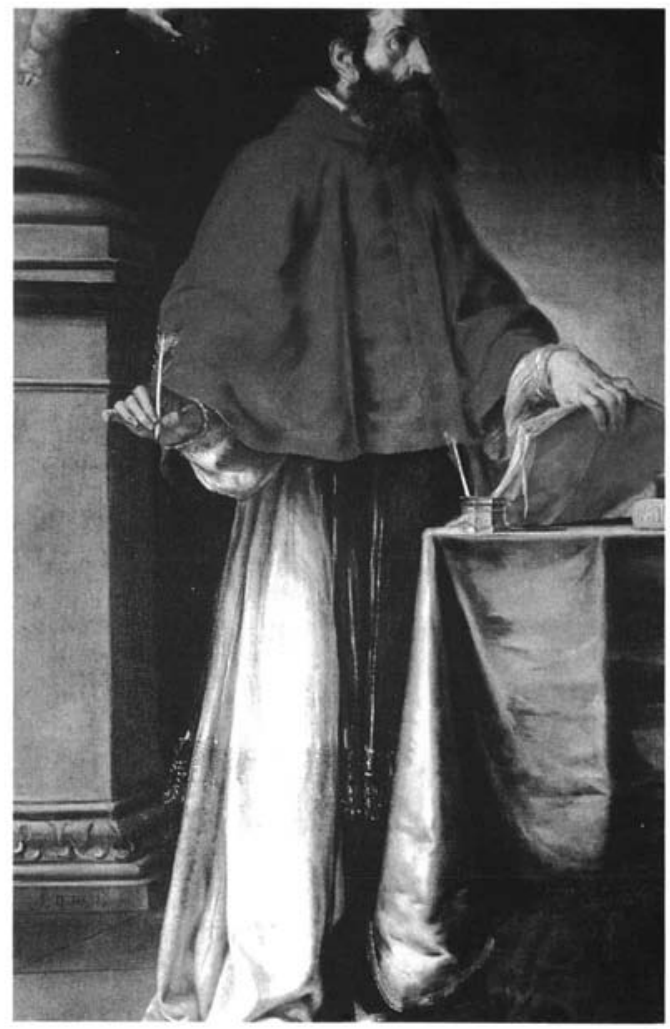

Figura I

San Jerónimo (detalle).

Museo del Prado (h. 1656-57). 


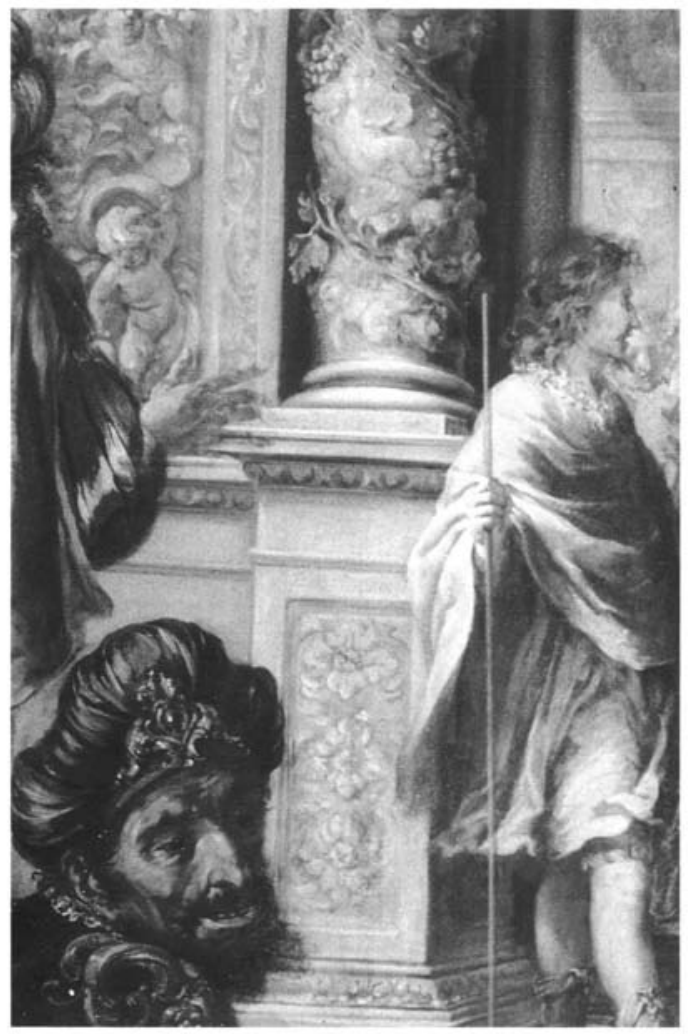

Figura 2

Pormenor de los Desposorios de ia Vï ken.

Catedral de Sevilla (1657). 


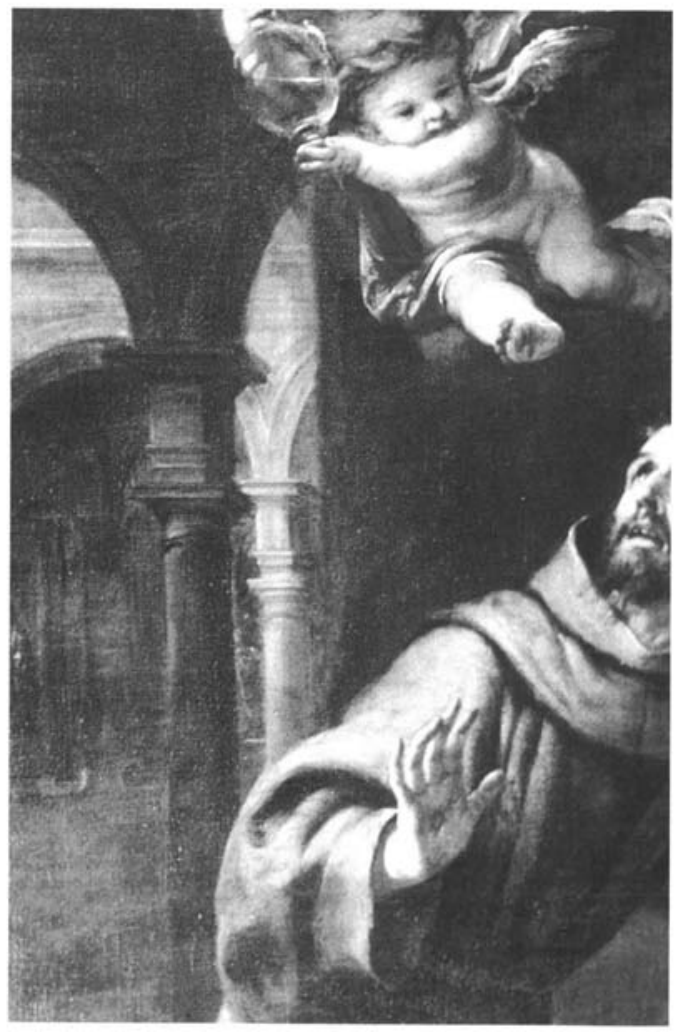

Figura 3

Pormenor de San Francisco recibiendo la ampolla de ayua. Museo de B. A. de Sevilla (h. I665). 


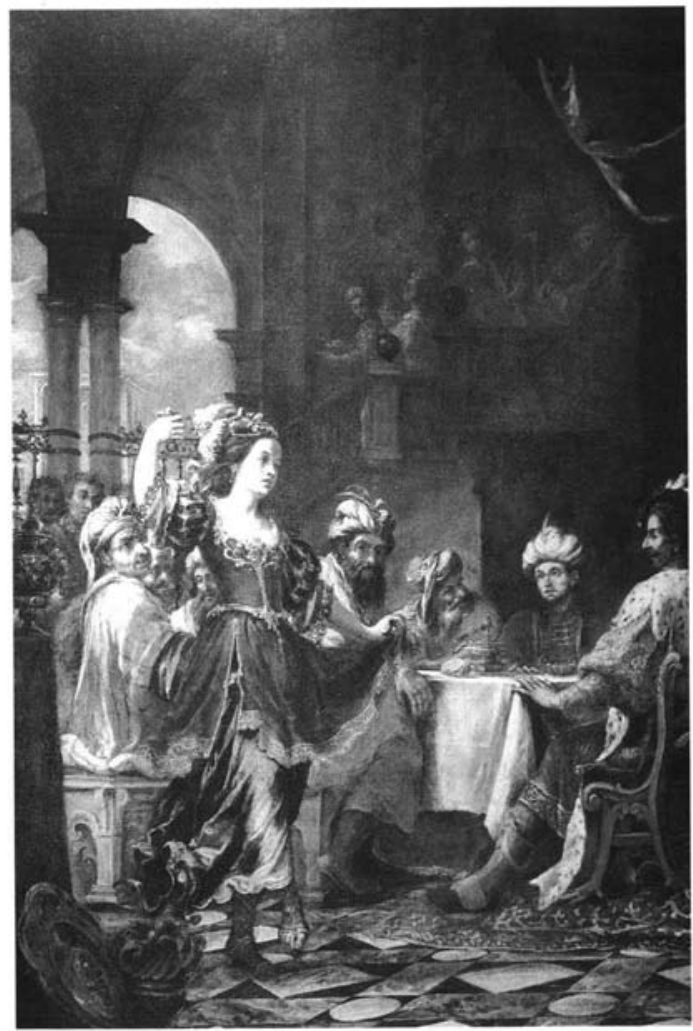

Figura 4

La dansa de Satamé

Madrid: Col. particular (h. 1676). 


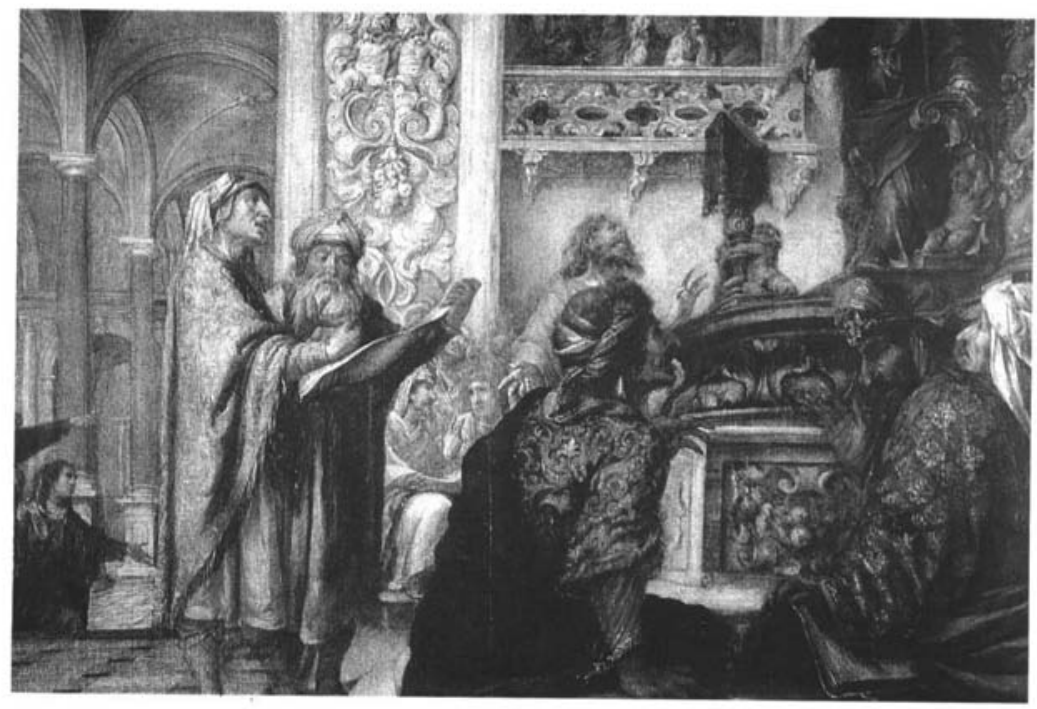

Figura 5 


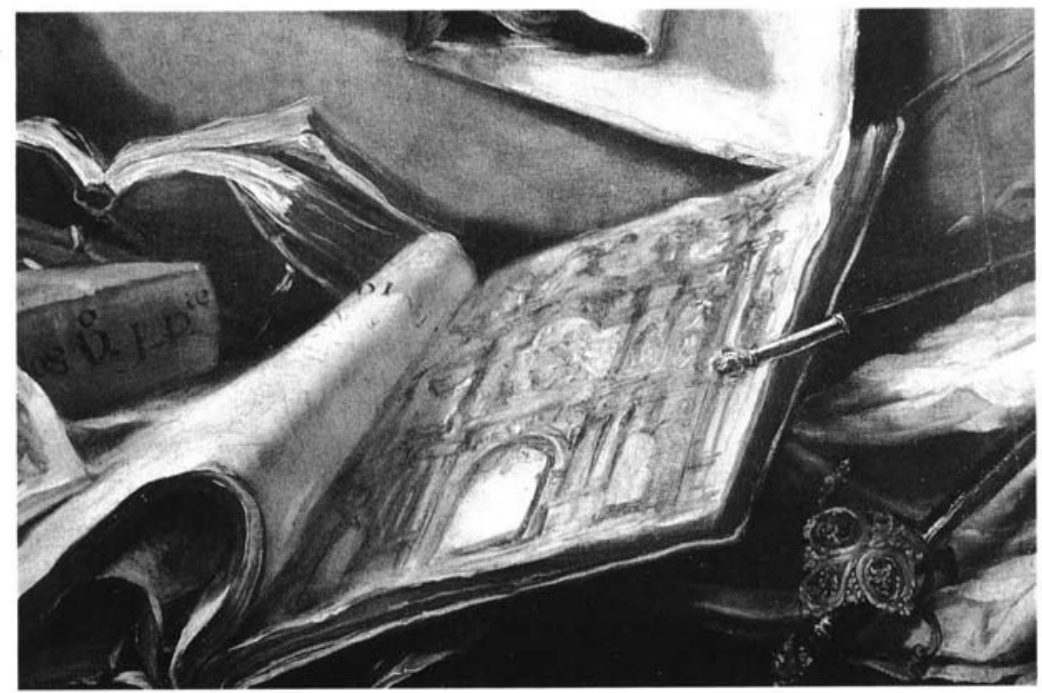

Figura 6

Pormenor de In Ictu oculi.

Iglesia del Hospital de la Caridad (h. 1671). 


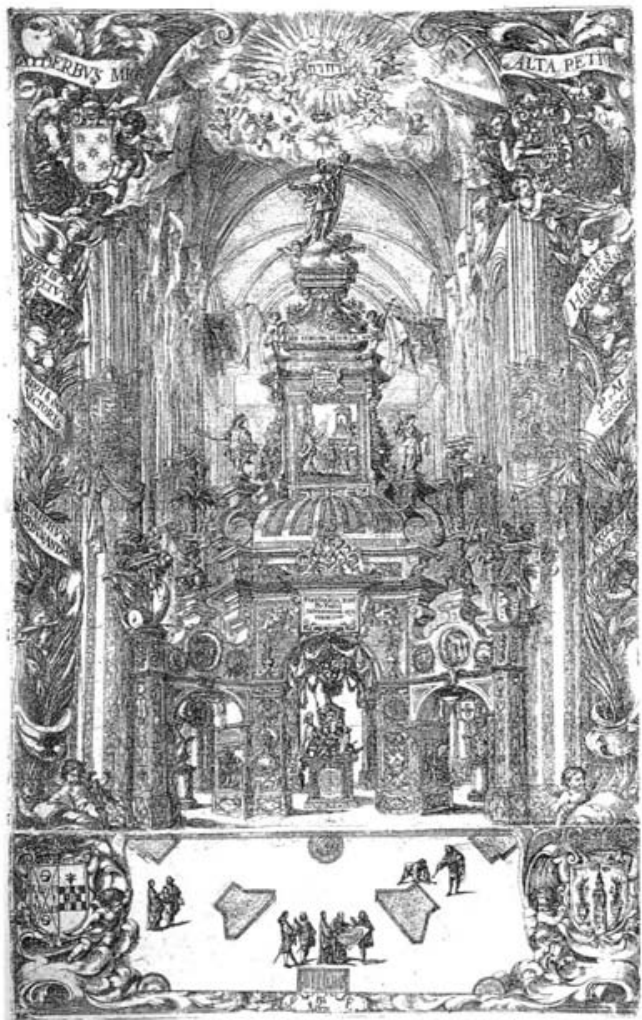

Figura 7

Triunfo de San Fernando.

Grabado de Valdés publicado por Torre Farfán en Fiestas de la Santa Iglesia... en 1671. 


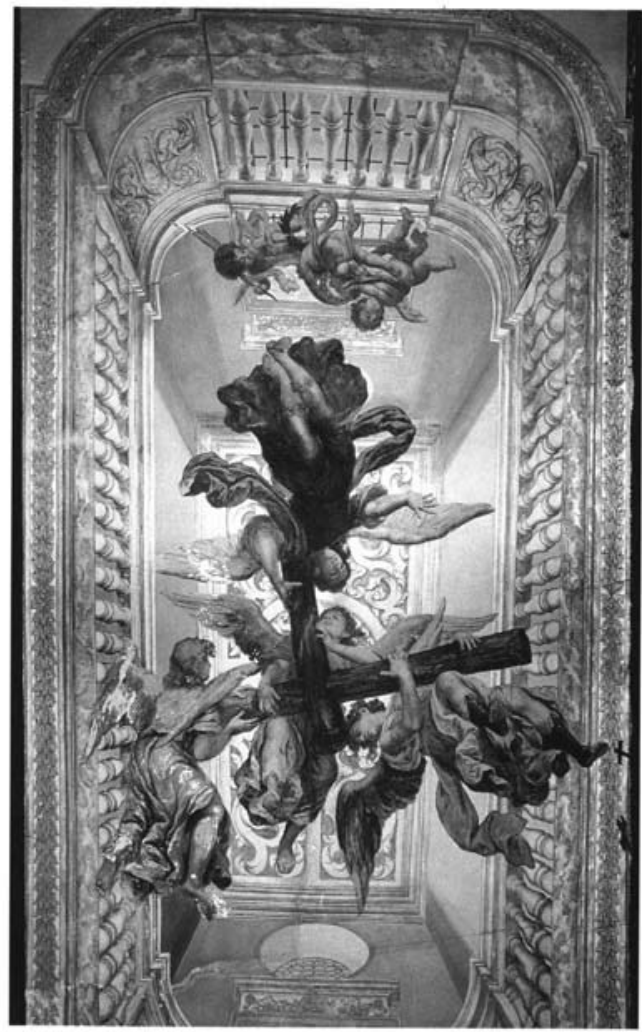

Figura 8

El triunfo de la Santa Crus.

Sacristía de la iglesia de los Venerables (1687-88). 